\title{
Günther Schmigalle (Estudio y edición), Rubén Darío. La caravana pasa. Sáenz Peña, Editorial de la Universidad Nacional de Tres de Febrero, 2019, Obras Completas de Rubén Darío, 456 páginas
}

\author{
Luis Alberto Salas Klocker
}

Cita sugerida: Salas Klocker, L. A. (2021). [Revisión del libro La caravana pasa por G. Schmigalle). Orbis Tertius, 26(33), e202. https://doi.org/10.24215/18517811e202

El tantas veces fallido proyecto de recopilar la obra completa de Rubén Darío presenta ahora un capítulo prometedor. La caravana pasa es la primera entrega de las tantas proyectadas para abarcar la totalidad de la obra conocida del poeta nicaragüense. Anteriores intentos han chocado con la dispersión y vastedad del objeto que pretendían aprehender. Este proyecto, auspiciado por la Universidad Nacional de Tres de Febrero a través del Programa de Estudios Latinoamericanos Contemporáneos y Comparados, parte de la constatación de este obstáculo y busca sortearlo en base al trabajo colaborativo de decenas de expertos y estudiosos a nivel mundial. La compleja red intelectual que Darío tejió en su tiempo en base a corresponsalías, epístolas y colaboraciones con diarios de muy variada naturaleza se reproduce hoy en aras de lograr una visión de conjunto de su canto errante. La instancia que aglutina los esfuerzos que vuelven posible esta obra es el Archivo Rubén Darío Organizado y Centralizado (AR.DOC), plataforma virtual libre y gratuita que apunta a democratizar el acceso a los materiales de archivo y que sirve como repositorio de aquellos textos que luego serán editados en volumen.

Las variables que vuelven pertinente un proyecto de estas características, en términos generales, son aún más significativas para La caravana pasa. Si consideramos que los principales problemas con los que ha tenido que lidiar la crítica dariana han sido la arbitraria manipulación de los textos, la fijación con algunos de ellos y el consiguiente olvido de los demás y lo inconseguible de los mejores trabajos críticos, La caravana pasa 
parecería ser el paradigma del derrotero del texto dariano. Originalmente publicado en 1902, no fue sino hasta el año 2000 que se reeditó de manera cuidadosa y atenta al texto original. Fue justamente Günther Schmigalle, editor de esta primera entrega de las obras completas de Darío, quien rescató este título y lo multiplicó en cuatro volúmenes críticos publicados entre 2000 y 2005. Ese trabajo nutre el presente, en lo que constituye un ejemplo más de esa suerte de capital dariano que promete llevar a buen puerto el presente proyecto.

La caravana pasa plantea, desde su edición original, una serie de interrogantes para el estudio de la obra dariana. Los textos que componen el volumen son crónicas publicadas por Darío en el diario La Nación entre 1901 y 1902. Fueron años de intensa labor periodística que quedan reflejados en el volumen en cuestión. Más de la mitad de dichas colaboraciones (treinta y cinco por sobre un total de sesenta y cuatro) hicieron ese camino del artículo periodístico al libro, un mecanismo que se repite en prácticamente toda la prosa dariana. Sin embargo, las semejanzas terminan en ese punto, ya que los textos incluidos en La caravana pasa fueron sometidos por el propio Darío a una serie de modificaciones que los vuelven excepcionales. Tal como marca Schmigalle, son por lo menos tres las operaciones que vuelven a La caravana pasa un objeto refractario, de una opacidad particular. En primer lugar, la elección del título. Aquel que posteriormente será el verso de un poema, "hacia Belén la caravana pasa", tiene su origen en un proverbio turco, que a su vez había sido recuperado por el poeta Jean Richepin y que está presente también en Marcel Proust (17). En segundo lugar, el borramiento del título, la fecha y el lugar de escritura de las crónicas. Este tipo de operaciones era habitual en Darío; sin embargo, La caravana pasa es un caso extremo porque los títulos son reemplazados apenas por números, escamoteando así aún más información para el lector. Y, finalmente, la decisión de agrupar los textos más por un criterio temático que por uno cronológico (Schmigalle, 2010: 41), en torno a cinco libros que tampoco llevan ningún tipo de referencia a su contenido.

Estas particularidades, según los testimonios de la época recuperados por Schmigalle, condicionaron la recepción del libro de Darío desde un primer momento. Sin embargo, lo que podría ser meramente una anécdota sobre malas decisiones editoriales tiene en realidad una significación más profunda en relación con la práctica escrituraria de Darío y del modernismo en general. Las figuraciones de autor que se ponen en juego con cada edición y el desplazamiento entre géneros y circuitos de circulación tan distintos entre sí remiten a la pregunta por la materialidad del oficio del escritor. Las incógnitas y los misterios logísticos en torno a la publicación transatlántica de las crónicas modernistas ocupan buena parte del estudio crítico que abre el volumen reseñado. No es un tema menor, ya que esclarecerlo ayudaría a entender de mejor manera el método de trabajo dariano, tan complejo como misterioso. Se sabe que Darío manejaba unos cuadernos en los que llevaba recortes y apuntes de una infinidad de temas; sin embargo, apenas se conserva uno de estos ejemplares (17). El destino de los manuscritos originales es un perfecto misterio. Ante este panorama, en principio hostil, la filología emerge como una opción. El cotejo minucioso que se hace de las versiones conocidas de cada texto, hasta cierto punto, desanda el camino que estos hicieron desde el manuscrito en París, pasando por su publicación en Buenos Aires y volviendo a Europa para convertirse en libro. El trazado de este derrotero permite reimaginar la manufactura del nicaragüense.

Esta aproximación de tipo material al oficio del escritor propicia, igualmente, consideraciones del tipo, podría decirse, idealista. Porque, en definitiva, las decisiones editoriales sobre un texto, ya sea este propio o ajeno, responden no solamente a condicionamientos materiales sino también a (pre)juicios estéticos. ¿Qué influyó en los primeros editores de Darío para que el Libro V desapareciera en su totalidad hasta la restitución que hiciera Schmigalle en el año 2000? ¿Fue acaso por la monotonía de las crónicas y su fijación con artistas hoy prácticamente olvidados? ¿ O, más bien, se trató de un descuido como el presente en la edición princeps, cuando se fusionaron en una dos crónicas referidas a exposiciones diferentes? Casualmente, son algunas de estas crónicas las que más llaman la atención a la crítica contemporánea e incluso han dado pie para la formulación de una categoría de análisis, como es la de salones darianos por parte del especialista Rodrigo Caresani (2018: 567). Junto a él, investigaciones como las de Laura Malosetti Costa (2001) y 
Beatriz Colombi (2017) han puesto en primera línea las crónicas darianas sobre arte, encontrando en ellas paradigmas estéticos que orientaron los distintos momentos del proyecto de Darío (Malosetti Costa, 2001: $380)$.

Tres de estas crónicas fueron parte de la edición original de La caravana pasa, por lo que la restitución a su contexto primero de publicación inscribe al volumen, hoy reeditado con un vasto aparato crítico, en una de las más activas líneas de investigación de los estudios darianos contemporáneos. Detrás de la sintaxis iterativa de estos textos, entonces, yacería lo que podría considerarse un subgénero dentro del repertorio dariano. Las crónicas sorprenden por su estabilidad, la cual apenas se ve perturbada por la irrupción de la imagen en el fugaz pero significativo paso de Darío por el Suplemento Semanal Ilustrado del diario La Nación. Los primeros de estos textos aparecen en 1895 en el diario La Prensa de Buenos Aires, en el que se publican siete crónicas dedicadas al Salón del Ateneo, posteriormente descubiertas por Malosetti Costa y recuperadas por Caresani. Las últimas serían en 1906, en París y para el diario La Nación. Esos once años abarcan un periodo creativo importantísimo para el nicaragüense: son los años en los que pasa de ser un recién llegado en la vida cultural argentina a ser el cronista estrella de uno de los diarios más importantes del momento. Son textos en los que se percibe un choque de códigos, el lingüístico y el visual, y en los que con mayor o menor éxito se ensaya una lógica intermedial que traduzca a las palabras lo que en imágenes todavía era muy difícil representar. Estas crónicas tienen características compartidas con las demás que conforman la serie de los salones darianos. En primer lugar, la selección de los cuadros reseñables solía estar guiada por el explícito gusto personal: "Digo y comunico lo que veo, tal como lo veo, tal como lo siento, con la sinceridad que me conocéis los que, desde hace catorce años, me habéis leído en La Nación” (238). Esto, sin embargo, no iba en desmedro de un diagnóstico más bien pesimista del estado del arte de su tiempo: "Insisto en mi sentir: ni uno ni otro presentan nada que domine en absoluto la admiración, como en los buenos tiempos en que el genio se hacía presente" (250). Como cronista urbano, no le faltaba un ojo atento a la sociabilidad en el campo cultural y a las reglas del arte: "El artista joven que sueña con ser recibido en el Salón, se desconsuela cuando sabe que se entra, por lo general, a golpe de recomendaciones y padrinazgos, y que el talento no es la condición primera" (239). Finalmente, en medio de tantos desengaños, el cronista desplegaba una retórica erudita puesta al servicio de orientar al espectador lego: "De M. Albert recomiendo su único cuadro expuesto, un amanecer holandés, en una ciudad vieja, con sus edificios y canales, y su juego de sol y bruma, que es de una gran belleza y de mucho saber" (244).

Las demás secciones que conforman el volumen están dedicados a la vida social y cultural de París (Libro I), a viajes por ciudades europeas (Libro II), a discusiones literarias (Libro III) y a asuntos diversos de interés mundial (Libro IV). Tal vez sea en el Libro III en el que más se percibe el efecto de sentido producto del reordenamiento de las crónicas. En su conjunto, el libro es un tratado sobre el estatuto del escritor en la modernidad. Tensionado entre las fuerzas anquilosantes de la academia, la tentación de la muerte como única garantía para alcanzar la fama y la absoluta indiferencia de sus connacionales, el arquetipo del poeta errante aparece bajo los nombres de Heine, Nervo, Heredia o Montalvo. En el caso de los latinoamericanos la situación parecería ser aún más dramática, ya que su patria electiva, que también es la de Heine, los ignora tanto como sus países de origen y los condena al ostracismo y la insignificancia (162). Los tres capítulos intermedios del Libro III parecen, así, una versión desangelada de una comunidad de raros. El primero y el último, en cambio, destacan el carácter medular del Libro III, el cual ocupa ese lugar no casualmente sino como eje conceptual del volumen. El capítulo I refiere a un "importante y curioso" (143) libro en el que se recopilan anécdotas sobre los difíciles inicios de varios escritores franceses, sobre sus estrecheces económicas y sobre el rechazo generalizado de la sociedad, lo que conecta con los dos primeros libros del volumen. Asimismo, el quinto capítulo, el menos literario de todos, se refiere al accidente de un globo aerostático brasileño y a los avances en la aeronavegación que "son lustre y orgullo, no solamente del Brasil, sino de la América toda” (179). La crónica, disruptiva respecto a las otras del Libro III, sugiere el pasaje a temas más generales, como los del Libro IV, con una historia que se debate entre "la trágica prosa de [los] infelices estrellados en pleno París" y "el poético descenso del personaje legendario a las aguas de un mar 
armonioso" (177). Así, una carrera que inicia con promesas de fama y reconocimiento en el capítulo I termina con hechos que tanto pueden ser materia mitológica como mera crónica roja.

El nutrido aparato crítico que reúne el volumen ilumina ciertas zonas de uno de los más misteriosos libros darianos. Tal como se plantea en el prólogo, la profusión de erratas en las primeras ediciones habla de publicaciones que no fueron revisadas por su autor, así como de un trabajo editorial desprolijo que Darío tuvo que padecer en buena parte de sus textos. Esta excelente primera entrega de sus Obras completas, de cierta forma, viene a subsanar aquello.

\section{REFERENCIAS}

Caresani, R. (2018). “Darío, entre Whistler y Ruskin”. Actas Congreso Internacional Rubén Dario: la sutura de los mundos (2016: Buenos Aires). Raúl Antelo et al. (comps.). Buenos Aires, Editorial de la Universidad Nacional de Tres de Febrero, 563-576. Recuperado de https://archivoiiac.untref.edu.ar/index.php/actas-del-congreso-in ternacional-la-sutura-de-los-mundos

Colombi, B. (2017). "Rubén Darío: supervivencia y mutación de las formas clásicas". Anales de Literatura Hispanoamericana, 46, 31-40. https://doi.org/10.5209/ALHI.58264

Malosetti Costa, L. (2001). Los primeros modernos: arte y sociedad en Buenos Aires a fines del siglo XIX. Buenos Aires, Fondo de Cultura Económica.

Shmigalle, G. (2010). "La caravana pasa de Rubén Darío: epítome del periodismo modernista". Rubén Darío: cosmopolita arraigado (pp. 41-53). J. Browitt y W. Mackenbach (eds.),Managua, Instituto de Historia de Nicaragua y Centroamérica, 41-53. 